\title{
Pterygium: new insights
}

\author{
Wai Kit Chu ${ }^{1} \cdot$ Hiu Lam Choi ${ }^{1,2} \cdot$ Amar K. Bhat $^{3} \cdot$ Vishal Jhanji ${ }^{1,3}$
}

Received: 21 November 2019 / Revised: 19 December 2019 / Accepted: 23 January 2020 / Published online: 6 February 2020

(c) The Author(s), under exclusive licence to The Royal College of Ophthalmologists 2020

\begin{abstract}
Pterygia are common conjunctival degenerations with well-documented risk factors but an unclear pathogenesis. Better understanding of the pathogenesis of pterygium could lead to improved surgical outcomes and decreased postoperative recurrence. Currently, pterygium excision with conjunctival autograft remains the preferred surgical technique to decrease pterygium recurrence. Many adjuvant therapies have been used in pterygium surgery to varying degrees of success. Topical cyclosporine, an immunosuppressive medication, in conjunction with conjunctival autograft was found to be most successful in decreasing pterygium recurrence according to a recent meta-analysis. Other adjuvant therapies such as mitomycin-C (MMC), 5-fluorouracil (5-FU), and beta-irradiation have also been used, though usage of these may cause multiple adverse effects. Recent research indicates that interactions between mouse double minute 2 (MDM2) and p53 could play a role in the occurrence of pterygium. Nutlin, an MDM2 antagonist, was found to have significantly less toxicity in conjunctival cells when compared with MMC on laboratory analysis of pterygium samples.
\end{abstract}

\section{Introduction}

Pterygia are fibrovascular degenerations of the conjunctiva that advance across the cornea over time [1]. The primary risk factors for pterygia are exposure to ultraviolet light, increasing age, and male gender [1-9]. Pterygia are usually located in the interpalpebral zone, more often nasal than temporal. Symptoms of pterygia include redness, irritation, dryness, tearing, and decreased vision. Decreased vision typically results from: (1) involvement of the visual axis, (2) induced astigmatism, and (3) tear film disruption.

Treatment for pterygia begins with conservative measures, such as lubricants and sunglasses. Surgery can be performed in cases where the patient desires symptomatic, optical, or cosmetic improvement. There are a variety of techniques employed in surgery for pterygia. Options after excising the pterygia include, primary closure of

Vishal Jhanji

jhanjiv@upmc.edu

1 Department of Ophthalmology \& Visual Sciences, The Chinese University of Hong Kong, Hong Kong, Hong Kong

2 Molecular Biotechnology Programme, School of Life Sciences, The Chinese University of Hong Kong, Hong Kong, Hong Kong

3 Department of Ophthalmology, University of Pittsburgh School of Medicine, Pittsburgh, PA, USA the conjunctiva, conjunctival autograft, limbal-conjunctival autograft (LCAG), conjunctival rotational graft, conjunctival flaps, and, amniotic membrane graft. Simple excisions leaving bare sclera lead to a high (38-88\%) recurrence rate [10]; currently, the gold standard for pterygia surgery is excision with conjunctival autograft due to its lower (1.9-8\%) recurrence rate [1]. LCAG aims to restore the anatomic integrity of the limbus and promote faster healing. In a meta-analysis, LCAG was found to have lower recurrence $(0-17 \%)$ compared with bare sclera, bulbar conjunctival autograft, and intraoperative MMC; no significant difference was found when compared with amniotic membrane grafts [11]. One meta-analysis noted that amniotic membrane grafts have higher recurrence rates $(3.7-40.9 \%)$ compared with conjunctival autograft (2.6-17.7\%), but amniotic membrane can be beneficial in patients with extensive conjunctival scarring or in patients that may need future glaucoma surgeries [12].

Recurrence after pterygium surgery can occur at the cornea or conjunctiva. Corneal recurrences, like primary pterygia, appear as fibrovascular growths of tissue across the limbus and onto the cornea. Conjunctiva recurrences manifest as a "bunching" of the conjunctiva. Risk factors for recurrence include: (1) young age, (2) fleshy, nontranslucent, and/or higher-grade pterygia, and (3) increased inflammation.

Some adjuvant therapies in pterygium surgery have also been studied: beta-irradiation, thiotepa, mitomycin-C 
(MMC), 5-fluorouracil (5-FU), anti-vascular endothelial growth factor (anti-VEGF), cyclosporine, and collagen implants.

(1) Beta-irradiation is a particulate radiation of highvelocity electrons that allows for focal radiation without deeper penetration into ocular tissues. Betairradiation after bare sclera excision led to a decreased $(0-11.8 \%)$ recurrence rate, but had potentially devastating complications: scleromalacia, necrosis, perforation, infective endophthalmitis, and sudden onset of mature cataract $[1,13]$.

(2) MMC is an alkylating agent that inhibits RNA, DNA, and protein synthesis. MMC is commonly used as a systemic anticancer drug but use in pterygium surgery is considered off label by the Food and Drug Administration. MMC has been used pre-, intra-, and post-operatively in pterygium surgery with varying degrees of success. MMC was found in some cases to cause scleral thinning, ulceration, and delayed conjunctival epithelialization [14]. One study noted an 8.3-8.6\% recurrence rate in patients who received MMC 0.02 or $0.04 \%$ MMC for $5 \mathrm{~min}$, but a $22.9-42.9 \%$ recurrence in patients who received the same treatment for only 3 min [15]. A 10-year study demonstrated $25.5 \%$ recurrence in the MMC group, compared with $6.9 \%$ in the LCAG group [16]. Nonetheless, MMC could be considered in cases of recurrent or high-grade pterygia.

(3) 5-FU is another commonly used anticancer drug that has been used off label in pterygium surgery. By inhibiting the $S$ (synthesis) phase of the cell cycle, 5-FU can decrease recurrence rate compared with surgery without 5-FU (5.83\% vs $25.5 \%$ ) [17]. 5-FU was found to have fewer complications than MMC or beta-irradiation.

(4) Anti-VEGF in conjunction with pterygium surgery has been attempted using subconjunctival injections and postoperative topical eye drops. Reported complications include corneal epithelial defects and erosions [18]. A recent meta-analysis of bevacizumab use in pterygium surgery showed decreases in recurrence rates with 12-month follow-up [19], although a prior meta-analysis did not find a significant decrease [20]. Recurrence rates after longer follow-up and the optimal method of anti-VEGF application are still to be determined.

(5) Topical cyclosporine has been shown to decrease recurrence in pterygium excision leaving bare sclera or using a conjunctival autograft [1]. Conjunctival autograft combined with cyclosporine was found to be the most successful intervention in preventing pterygium recurrence in a 2017 meta-analysis. In vitro studies demonstrated the inhibitory effect of cyclosporine on fibroblast proliferation.

(6) Collagen matrix implants aim to induce regenerative but nonscarring wound healing. Implants are biodegraded within 90-180 days. Conjunctiva was found to have less inflammation and patients reported less pain and discomfort compared with MMC and LCAG. A 2013 study comparing bare sclera vs collagen matrix implants demonstrated no significant decrease in recurrence, but the sample size (10 in each group) was not adequate for determining significance [21]. Collagen matrix implants combined with conjunctival autograft were found to be beneficial in two cases of suspected MMC-associated scleral thinning after pterygium excision [22].

A 2017 network meta-analysis comparing the multiple adjuvant treatments for primary pterygium analysed the results of 24 separate randomized, controlled trials that utilized 14 different interventions [1]. The meta-analysis findings included that conjunctival autograft with cyclosporine $0.05 \%$ eye drops was most successful in preventing recurrence. The authors of the meta-analysis noted that the technique with the highest recurrence was pterygium excision leaving bare sclera without adjuvant treatment. One main limitation of the meta-analysis was the limited length of follow-up (3 months) for some included studies, though longer minimum follow-up times would further decrease the number of studies available for analysis.

\section{Role of $p 53$}

The pathogenesis of pterygium is not clear. Multiple studies have reported that the expression of p53 and MDM2 (mouse double minute 2) proteins are elevated in pterygium [23-26]. p53 is a tumor suppressor protein that could induce apoptosis and restrict the growth of cancer [27, 28]. MDM2 is an E3 ubiquitin ligase that acts as an antagonist of p53 and binds to p53 to inhibit its transcriptional ability [29]. Our previous study showed that both p53 and MDM2 had elevated expression levels in pterygium tissues compared with the conjunctiva [23]. In conjunctiva, p53 expression was undetectable and only very weak expression of MDM2 was observed. However, both p53 and MDM2 showed strong expression in pterygium [23]. These results are consistent with a previous report that overexpression of p53 was identified in pterygium with or without recurrence [26]. Another report found that p53 expression was detected in the basal layer of pterygium epithelial cells [30]. In addition, we observed an intracellular localization difference between p53 and MDM2 in pterygium [23]. In pterygium, p53 was mainly localized in the cytoplasm, while most of 
the MDM2 accumulated in nuclei. These findings suggest the cytoplasmic p53 is not efficient in inducing apoptosis in pterygium, despite of its high expression level. Furthermore, p21 is one of the transcriptional targets of p53. We found that the 21 protein was not detectable in pterygium tissues, suggesting the p53 transcriptional activity was not active in pterygium [23]. Chemical agents including Nutlin have been developed to bind to the interface between p53 and MDM2, which is able to disturb the binding between MDM2 and p53 and to activate p53 [31]. We also treated pterygium cells with Nutlin and found that more p53 could be detected in nucleus. Furthermore, p21 expression and apoptosis could be induced in Nutlin treated pterygium cells $[23,32]$. Our results suggest that disrupting the MDM2-p53 interaction could lead to p53 localizing in nucleus and p53 reactivation.

To treat the pterygium, surgical excision is one of the commonly used methods, but the recurrence rate can be high after its surgical removal [32]. Intraoperative MMC treatment is commonly applied to reduce the recurrence of pterygium [16, 33]. MMC is a natural anti-tumor antibiotic that could generate cross-links on the DNA strands [34]. It was shown that MMC caused significant reduction in cell viability and migration in both conjunctiva and pterygium [32]. We also treated the pterygium and conjunctiva cells with Nutlin. Significant reductions in viability and migration were detected in pterygium cells, while no significant change in the conjunctival cell survival and migration could be observed [32]. Comparing the effects of Nutlin and MMC treatments in conjunctiva, we found that at the concentration of killing $50 \%$ of pterygium cells, $95 \%$ conjunctival cells survived after Nutlin treatment. However, only $63 \%$ conjunctival cells survived when treated with MMC at the concentration that killed half of pterygium cells [32]. Our results suggest that Nutlin could be more specific than MMC in killing pterygium cells with less adverse impacts on conjunctiva cells.

\section{Conclusions}

Pterygia are common fibrovascular growths with an unclear pathogenesis that may involve MDM2 and p53 interaction. The current gold standard treatment for clinically significant pterygium is excision with conjunctival autograft, as this has demonstrated a low recurrence rate that has been reproduced in multiple studies. Numerous other techniques to decrease recurrence rate exist, such as application of MMC, which is associated with multiple adverse effects. On laboratory analysis of pterygium samples, Nutlin treatment led to significantly less toxicity of conjunctival cells when compared with MMC.
The current literature recommends the following:

(1) Pterygium excision with conjunctival (or limbalconjunctival) autograft remains the current standard of care for primary pterygium. Due to high recurrence rates, simple excision of pterygium leaving bare sclera should not be performed.

(2) The current adjunctive therapies to pterygium excision with conjunctival autograft include antimetabolites and anti-VEGF. Although they may play a role in decreasing pterygium recurrence, they might be associated with adverse effects that make them difficult to recommend for routine, primary pterygium excision.

(3) There is evidence that targeting the MDM2-p53 pathway could help understand the pathogenesis of pterygium and propose novel therapies to decrease recurrence rate after surgery.

\section{References}

1. Fonseca EC, Rocha EM, Arruda GV. Comparison among adjuvant treatments for primary pterygium: a network meta-analysis. Br J Ophthalmol. 2018;102:748-56.

2. Lu P, Chen X, Kang Y, Ke L, Wei X, Zhang W. Pterygium in Tibetans: a population-based study in China. Clin Exp Ophthalmol. 2007;35:828-33.

3. McCarty CA, Fu CL, Taylor HR. Epidemiology of pterygium in Victoria, Australia. Br J Ophthalmol. 2000;84:289-92.

4. Durkin SR, Abhary S, Newland HS, Selva D, Aung T, Casson RJ. The prevalence, severity and risk factors for pterygium in central Myanmar: the Meiktila Eye Study. Br J Ophthalmol. 2008;92:25-9.

5. Viso E, Gude F, Rodríguez-Ares MT. Prevalence of pinguecula and pterygium in a general population in Spain. Eye. 2011;25:350-7.

6. Zhao L, You QS, Xu L, Ma K, Wang YX, Yang H, et al. 10-year incidence and associations of pterygium in adult Chinese: The Beijing Eye Study. Investig Ophthalmol Vis Sci. 2013;54:1509-14.

7. Marmamula S, Khanna RC, Rao GN. Population-based assessment of prevalence and risk factors for pterygium in the South Indian State of Andhra Pradesh: The Andhra Pradesh Eye Disease Study. Investig Ophthalmol Vis Sci. 2013;54:5359-66.

8. Nangia V, Jonas JB, Nair D, Saini N, Nangia P, Panda-Jonas S. Prevalence and associated factors for pterygium in rural agrarian central India. The central India eye and medical study. PLoS ONE. 2013;8:e82439.

9. Yang Q, Jhanji V, Tan SQ, Chan KP, Cao D, Chu WK, et al. Continuous exposure of nicotine and cotinine retards human primary pterygium cell proliferation and migration. J Cell Biochem. 2019;120:4203-13.

10. Janson BJ, Sikder S. Surgical management of pterygium. Ocul Surf. 2014;12:112-9.

11. Zheng K, Cai J, Jhanji V, Chen H. Comparison of pterygium recurrence rates after limbal conjunctival autograft transplantation and other techniques: meta-analysis. Cornea. 2012;31:1422-7.

12. Li M. Comparison of conjunctival autograft transplantation and amniotic membrane transplantation for pterygium: a Metaanalysis. Graefes Arch Clin Exp Ophthalmol. 2012;250:375-81. 
13. Ali AM, Thariat J, Bensadoun RJ, Thyss A, Rostom Y, El-Haddad $\mathrm{S}$, et al. The role of radiotherapy in the treatment of pterygium: a review of the literature including more than 6000 treated lesions. Cancer/Radiothérapie. 2011;15:140-7.

14. Kaufman S. Options and adjuvants in surgery for pterygium: a report by the Ameraican Academy of Ophthalmology. Ophthalmology. 2013;120:201-8.

15. Lam DS, Wong AK, Fan DS, Chew S, Kwok PS, Tso MS. Intraoperative mitomycin $\mathrm{C}$ to prevent recurrence of pterygium after excision: a 30-month follow-up study. Ophthalmology. 1998;105:901-4.

16. Young AL, Ho M, Jhanji V, Cheng LL. Ten-year results of a randomized controlled trial comparing $0.02 \%$ mitomycin $\mathrm{C}$ and limbal conjunctival autograft in pterygium surgery. Ophthalmology. 2013;120:2390-5.

17. Silva R, Avila M, Rassi A, Ximenes L, Silva D, Paula A. Intraoperative use of 5-fluorouracil in pterygium. Surg. 2013;28: 34-6.

18. Fallah MR, Khosravi K, Hashemian MN, Beheshtnezhad AH, Rajabi MT, Gohari M. Efficacy of topical bevacizumab for inhibiting growth of impending recurrent pterygium. Curr Eye Res. 2010;35:17-22.

19. Sun Y, Zhang B, Jia X, Ling S, Deng J. Efficacy and safety of bevacizumab in the treatment of pterygium: an updated meta-analysis of randomized controlled trials. J Ophthalmol. 2018;2018:4598173.

20. Hu Q, Qiao Y, Nie X, Cheng X, Ma Y. Bevacizumab in the treatment of pterygium: a meta-analysis. Cornea. 2014;33:154-60.

21. Arish M, Nadjafi AN, Jahangard M. Collagen matrix implantation following pterygium excision: outcomes of a preliminary tested hypothesis. Med Hypothesis Disco Innov Ophthalmol. 2013;2: $102-4$.

22. Cho $\mathrm{CH}$, Lee SB. Biodegradable collagen matrix $\left(\right.$ Ologen $^{\mathrm{TM}}$ ) implant and conjunctival autograft for scleral necrosis after pterygium excision: two case reports. BMC Ophthalmol. 2015; $15: 140$.
23. Cao D, Ng TK, Yip YWY, Young AL, Pang CP, Chu WK, et al. p53 inhibition by MDM2 in human pterygium. Exp Eye Res. 2018;175:142-7.

24. Tsai YY, Chang KC, Lin CL, Lee H, Tsai FJ, Cheng YW, et al. p53 Expression in pterygium by immunohistochemical analysis: a series report of 127 cases and review of the literature. Cornea. 2005;24:583-6.

25. Tsai YY, Cheng YW, Lee H, Tsai FJ, Tseng SH, Chang KC. P53 gene mutation spectrum and the relationship between gene mutation and protein levels in pterygium. Mol Vis. 2005;11:50-5.

26. Weinstein O, Rosenthal G, Zirkin H, Monos T, Lifshitz T, Argov $\mathrm{S}$. Overexpression of p53 tumor suppressor gene in pterygia. Eye. 2002;16:619-21.

27. Fridman JS, Lowe SW. Control of apoptosis by p53. Oncogene. 2003;22:9030-40.

28. Ozaki T, Nakagawara A. Role of p53 in cell death and human cancers. Cancers. 2011;3:994-1013.

29. Nie L, Sasaki M, Maki CG. Regulation of p53 nuclear export through sequential changes in conformation and ubiquitination. J Biol Chem. 2007;282:14616-25.

30. Tan DT, Tang WY, Liu YP, Goh HS, Smith DR. Apoptosis and apoptosis related gene expression in normal conjunctiva and pterygium. Br J Ophthalmol. 2000;84:212-6.

31. Vassilev LT, Vu BT, Graves B, Carvajal D, Podlaski F, Filipovic $\mathrm{Z}$, et al. In vivo activation of the p53 pathway by small-molecule antagonists of MDM2. Science. 2004;303:844-8.

32. Cao D, Chu WK, Ng TK, Yip YWY, Young AL, Pang CP, et al. Cellular proliferation and migration of human pterygium cells: mitomycin versus small-molecule inhibitors. Cornea. 2018;37:760-6.

33. Tsim NC, Young AL, Jhanji V, Ho M, Cheng LL. Combined conjunctival rotational autograft with $0.02 \%$ mitomycin $\mathrm{C}$ in primary pterygium surgery: a long-term follow-up study. $\mathrm{Br} \mathrm{J}$ Ophthalmol. 2015;99:1396-400.

34. Tomasz M. Mitomycin C: small, fast and deadly (but very selective). Chem Biol. 1995;2:575-9. 